${ }^{1}$ Dentistry course, School of Medicine and Public Health of Bahia (BAHIANA). Salvador-Ba, Brazil.

${ }^{2}$ Institute of Health Sciences, Federal University of Bahia (UFBA). Salvador-Ba, Brazil.

${ }^{3}$ Kings College London Dental Institute, King's College London, London, UK.

${ }^{4}$ School of Dentistry, Federal University of Bahia (FOUFBA). Salvador-Ba, Brazil.
Corresponding author: Luana Mendonça Dias School of Medicine and Public Health of Bahia (BAHIANA) Av Silveira Martins, n.3386, Cabula. 41150-100, Salvador-Ba, Brazil. email: luanadias.1@hotmail.com

Received: November 28, 2018 Accepted: May 23, 2019

\section{Can surface protection prevent damage in margins of composite resin restorations after simulated endogenous erosion?}

\author{
Luana Mendonça Dias ${ }^{1, *}$, Janaina Emanuela \\ Damasceno ${ }^{1}$, Patricia Akemi Nishitani Shibasaki ${ }^{1}$, Max \\ José Pimenta Lima², Roberto Paulo Correia de Araújo², \\ Richard Mark Foxton ${ }^{3}$, Andrea Nóbrega Cavalcanti ${ }^{1,4}$
}

Aim: The study investigated the effect of using surface protection agents in the adaptation of external and internal margins of restorations subjected to simulated erosion. Methods: Cavities with margins in dentin were prepared in bovine incisors $(n=120)$. Adhesive restorations were placed using a three-step etch\&rinse adhesive system and nanofilled composite resin. The specimens were divided into four groups, according to the surface protection: negative control, topical application of fluoride (TAF), resin sealant and resin-modified glass ionomer varnish (RMGI varnish). Afterwards, they were divided into three sub-groups, according to the exposure to a simulated solution of gastric acid (DES) $(5 \% \mathrm{HCl}, \mathrm{pH}=2,2)$ and subsequent remineralization (RE): negative control, 9 and 18 cycles of DES-RE. The evaluation of the tooth-restoration interface was performed on the internal and frontal images with the aid of a stereoscopic microscope (15x), and the percentage of continuous margins without adhesive failures was quantified. Results: In the external margins, only those groups with surface protection using sealants (resin and glass-ionomer) did not exhibit a significant decrease in the percentage of continuous margins after the erosive challenges. After 18 cycles of DES-RE, the use of resin-modified glass ionomer varnish resulted in the highest percentage of continuous margins. Conclusion: It was concluded that physically covering the surfaces with a sealing agent preserved the marginal adaptation of composite resin restorations exposed to endogenous erosive challenges.

Keywords: Dentin; erosion; acid gastric. 


\section{Introduction}

Erosion is defined as a localized loss of hard dental tissue caused by exposure of dental surfaces to extrinsic or intrinsic acids, unrelated to bacterial metabolism ${ }^{1}$. This demineralization by acid can have an endogenous etiology, characterized by intrinsic factors, such as gastric acid; an exogenous etiology, characterized by extrinsic factors, such as; sugar, dietary soft drinks, fruit juices, carbonated beverages; and an idiopathic etiology, when the diagnosis is not possible through anamnesis or clinical examination.

The erosive challenge occurs in a progressive way and results in the loss of surface structure. It initially affects enamel followed by dentin, making the tooth brittle and more susceptible to wear by brushing or masticatory forces ${ }^{2}$, also compromising the dental anatomy and the vertical dimension of occlusion ${ }^{3}$.

Resin composite restorative materials represent one of the many biomaterial research successes ${ }^{4}$ and are frequently used for the rehabilitation of sequels resulting from endogenous erosion ${ }^{5}$. Composite resin is considered to be less susceptible to erosive challenges when compared to dentin and other restorative materials, but the acid attack can still induces matrix degradation and loss of filler particles ${ }^{6}$. There is evidence that chemical degradation of the composite resins can occur because of the diffusion of un-reacted monomers molecules and ions ${ }^{7}$. An increase in surface roughness and softening can occur, resulting in alterations by ruptures of small fragments, as well as accumulation of bacterial plaque ${ }^{6}$.

Endogenous erosion is a condition, which is difficult to control, and preventive measures are necessary for the preservation of both the remaining dental structure and the surface of restorative materials used for rehabilitation. One option is to use fluoride ions in various sources, or physical barriers against the contact of acids, such as glass ionomer and resin sealants, however the most appropriate treatment has yet to be determined ${ }^{8-13}$. Therefore the aim of the present study to evaluate the effectiveness of different methods of surface protection in maintaining the quality of the margins of restorations in the composite resin, submitted to acid challenges of endogenous origin, in order to extend the longevity of restorative materials in the oral environment. The hypothesis tested was that a resin-modified glass ionomer varnish, a resin sealant and a topical application of $2 \%$ neutral fluoride would have potential to prevent damages in the dentine-composite resin interface of adhesive restorations, in situations of endogenous dental erosion.

\section{MATERIALS AND METHODS}

\section{Obtaining the test specimens}

120 bovine incisors were obtained, cleaned with scalpel blades to remove organic debris and polished with pumice paste, using Robson's brushes in counter angle of low rotation. The teeth were visually examined for confirmation of the absence of physical damage that would compromise the study, such as discoloration, cavities, and cracks. 
The selected teeth were stored in 0.1\% thymol solution (Cromato Produtos Químicos LTDA, Diadema - SP - Brazil) until the moment of use, when they were placed in saline solution. The teeth were cut with a double-sided diamond disc (n.7020, KG Sorensen, Cotia - SP - Brazil), casting aside the root and sectioning the vestibular face in the mesial-distal and incisor-occlusal directions to obtain similar sized fragments.

Each fragment was individually mounted in polystyrene resin and the enamel of the vestibular face was ground until dentin was exposed using abrasive discs of descending grit (\#400 e \#600, Vonder - ODV, Feira de Santana - BA - Brazil), in a polishing machine (Arotec, S/A Industria e Comercio, Cotia - SP - Brazil) under constant cooling.

The area exposed to erosion challenge was delimited using a $6 \mathrm{~mm}$ diameter adhesive tape. The entire surface of the dentin, besides this delimitation was covered with 2 layers of nail polish in red color. After drying the varnish, the adhesive tape was removed and, at the center of the dentine delineation, $2 \times 2 \mathrm{~mm}$ cylindrical cavities were made with diamond burs (n.2294, KG Sorensen, Cotia - SP - Brazil), which were replaced every 10 cavity preparations. At the end, a limit of $2 \mathrm{~mm}$ around each cavity was established for the erosion challenge.

The adhesive procedure was performed using a three-step etch \& rinse system (Scotchbond Multipurpose Plus, 3M-ESPE, Sumaré - SP - Brazil), according to the manufacturer's recommendations. Conditioning of the cavities was performed using 37\% phosphoric acid for 15 seconds (Biodinamica Quim, e Farm. LTDA, Ibiporã - PR - Brazil), washing and drying with absorbent paper. The application of the primer was done actively, followed by drying with a light jet of air for 5 seconds at $10 \mathrm{~cm}$. After application, the adhesive was photo-activated for 10 seconds with a light-curing unit of $1500 \mathrm{~mW} / \mathrm{cm}^{2}$ light intensity (Radii Plus, SDI Brasil Industria e Comercio LTDA, São Paulo - SP - Brazil).

The composite resin restorations (FiltekZ350, color A3B, 3MESPE, Sumaré - SP Brazil) were performed in a single layer. After insertion of the composite, a polyester matrix tape was placed on the surface and photoactivation was performed. Polishing of the restorations was performed 24 hours later using sandpaper discs in a descending sequence of abrasiveness (Sof-Lex Pop-on, 3M-ESPE, Sumaré - SP - Brazil). The quality of the margin finishing was verified with a stereoscopic microscope (Opton, Parque Industrial San José, Cotia - SP - Brazil), with 15x magnification.

After specimens were fabricated, they were randomly allocated into twelve experimental groups $(n=10)$ in accordance with the method of preventing the effects of erosive challenge and the intensity of erosive simulation by gastric acid (Figure 1).

\section{Methods of preventing the effects of erosive challenge}

The methods were performed as described below:

- Negative control: The units belonging to this group did not suffer any changes in their restored surfaces, only maintained at relative humidity at $37^{\circ} \mathrm{C}$.

- Topical application of fluoride (TAF): On each surface, $1 \mathrm{ml}$ of $\mathrm{NaF}$ gel (neutral fluoride gel, 2\%, DFL Industria e Comercio SA, Jacarepaguá - RJ - Brazil) was ap- 


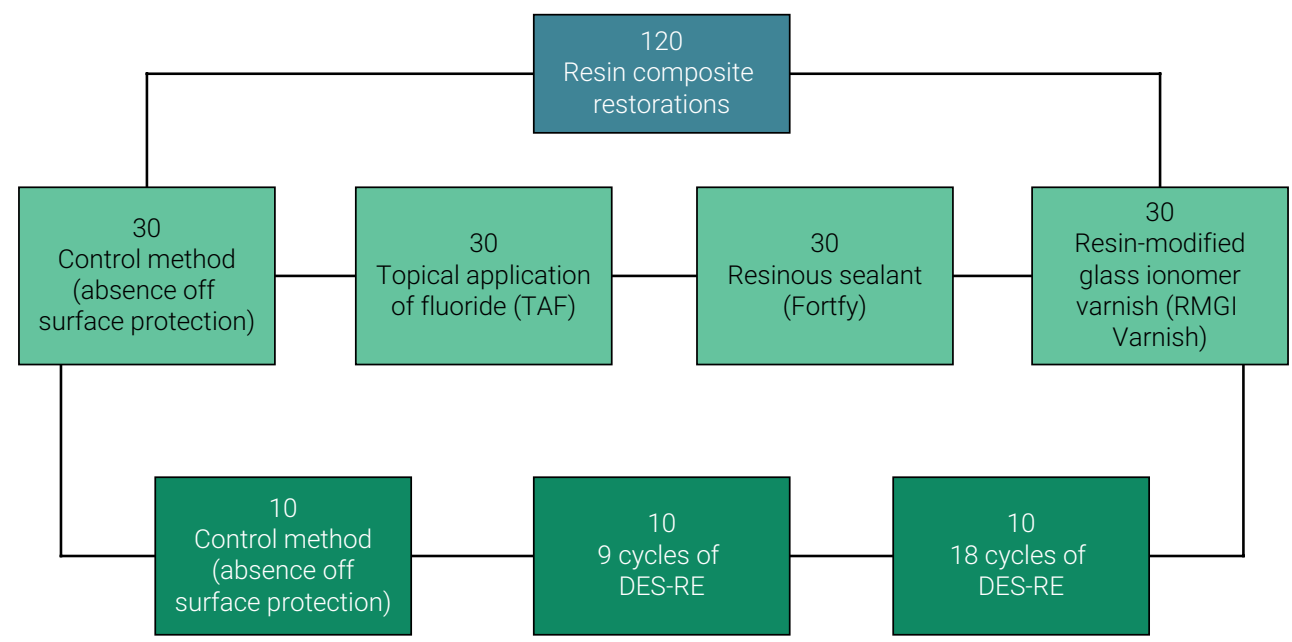

Figure 1. Distribution of the control method and levels of erosive challenge.

plied for 1 minute, then washed with distilled water in an ultrasonic bath (UNIQUE Indústria And Comercio LTDA, São Paulo - SP - Brazil) for 2 minutes. Afterwards, they were stored in relative humidity of $37^{\circ} \mathrm{C}$.

- $\quad$ Resin-modified glass ionomer varnish (RMGI Varnish): The application of the material (Clinpro XT Varnish, 3M-ESPE, St Paul, MN, USA) followed the manufacturer's recommendations. The components of the RMGI Varnish were applied to a paper surface and quickly mixed for 15 seconds and applied in a thin layer on the surface with the aid of a disposable applicator. Then, photoactivation was performed for 20 seconds, after which time, they were stored at relative humidity at $37^{\circ} \mathrm{C}$.

- Resin sealant: The restored surface was conditioned with 37\% phosphoric acid for 15 seconds, washed abundantly and dried with air jets, at a distance of 10 $\mathrm{cm}$. A thin layer of the resin sealant (Fortify, BIOSCO Inc., Shaumburg - USA) was actively applied to the surface of the composite resin, and then the surface was photo-activated for 10 seconds.

\section{Simulation of erosion by gastric acid}

After applying the respective preventive method, the treated specimens were randomly distributed according to the conditions of the simulated erosion. Therefore, the 4 experimental groups were subdivided into 3 subgroups $(n=10)$, as follows:

- Exposure control: the cavities in this subgroup were immersed in $10 \mathrm{ml}$ of distilled water at $37^{\circ} \mathrm{C}$ and were not subjected to any solution during execution of cycles of the other subgroups.

- Frequency of 9 cycles of DES-RE: Each complete cycle consisted of immersion in $10 \mathrm{ml}$ of hydrochloric acid solution $(5 \% \mathrm{HCl} \mathrm{pH}=2.2)$ for 2 minutes at room temperature. After demineralization, the specimen was washed in $20 \mathrm{ml}$ of distilled water in an ultrasonic bath for 2 minutes and immersed for 60 minutes in the remineralizing solution $(1.5 \mathrm{mmol} / \mathrm{L} \mathrm{Ca}, 0.9 \mathrm{mmoll} / \mathrm{L} \mathrm{PO} 4,0.15 \mathrm{~mol} / \mathrm{L} \mathrm{KCl}$, and $20 \mathrm{mmol} / \mathrm{L}$ TRIS buffer at $\mathrm{pH} 7.0)^{14}$. Then, the specimen was washed in $20 \mathrm{ml}$ of 
distilled water in an ultrasonic washer (UNIQUE Industria e Comercio LTDA, São Paulo - SP - Brazil) for 2 minutes. Between the cycles, the units were stored in relative humidity, at $37^{\circ} \mathrm{C}$.

- Frequency of 18 cycles of DES-RE: The specimens of this subgroup were subjected to double the frequency of cycles in order to promote a more aggressive challenge. Each cycle was performed as previously described.

The methodology about simulation of erosion the use in present study was based on the work of de Queiroz et al. ${ }^{15}$.

\section{Evaluation of marginal adaption}

Examination of the specimens was mediated by a calibrated examiner, who recorded the percentage of continuous margins using a stereoscopic microscope, which captured the images at 15x magnification. The margin was first analyzed with the aid of CorelDRAW, an image processing program.

The method of this evaluation was adapted from the work of Bortolotto et al. ${ }^{16}$, and the captured images were classified in percentages of "continuous margins" - absence of gaps, interruptions and total continuity of margin and percentage of "non-continuous margins" - presence of gaps by adhesive and cohesive failure, fracture of restorative material or dental substrate.

After the analysis of the external margins, the specimens were adapted to an acrylic plate with the aid of sticky wax (NewWax, Technew Com. Ind. Ltda, Rio de Janeiro $\mathrm{RJ}$ - Brazil) and sectioned in two parts, dividing the center of the cavity with the aid of a diamond cutting disc adapted to a precision cutter (Extec Corp. ${ }^{\circledR}$, Enfield CT - USA), with a diamond disk (Extec Corp. ${ }^{\circledR}$, Enfield CT - USA). This procedure was performed to reveal internal margins for the purpose of analyzing them, using the same image-processing program previously described.

\section{STATISTICAL ANALYSIS}

Initially the exploratory analysis of the data was performed to verify the homogeneity of the variances and to determine if the experimental errors presented a normal distribution (parameters Analysis of Variance). Inferential statistical analysis was performed by 2-Way ANOVA and Tukey's test for multiple comparisons. This analysis was done using SAS statistical software, version 9.1, with significance level of $5 \%$.

\section{RESULTS}

\section{External margin}

Table 1 shows the average and standard deviation of the \% of external continuous margin found in the experimental groups. According to the statistical analysis of the data, a significant interaction was observed between the factors "prevention method" and "erosive challenge" ( $p=0.04)$, indicating dependence between levels of one factor on the results of the other. This statistical interaction was deployed by the Tukey's test. 
Table 1. Mean (standard deviation) of experimental groups - External margin

\begin{tabular}{lccc}
\hline \multirow{2}{*}{ Erosive challenge control methods } & \multicolumn{3}{c}{ Erosive Challenge } \\
\cline { 2 - 4 } & Negative control & 9 cycles & \multicolumn{1}{c}{$\mathbf{1 8}$ cycles } \\
\hline Negative control & $99.2(1.7) \mathrm{Aa}$ & $90.8(5.1) \mathrm{Ab}$ & $84.1(6.7) \mathrm{Bb}$ \\
\hline Topical application of fluoride & $97.8(3.3) \mathrm{Aa}$ & $89.9(5.4) \mathrm{Ab}$ & $89.8(8.8) \mathrm{ABb}$ \\
\hline Resin-modified glass ionomer varnish & $99.0(3.0) \mathrm{Aa}$ & $95.8(2.8) \mathrm{Aa}$ & $93.1(7.8) \mathrm{Aa}$ \\
\hline Resin sealant & $94.6(5.2) \mathrm{Aa}$ & $92.3(2.3) \mathrm{Aa}$ & $89.9(5.4) \mathrm{ABa}$ \\
\hline
\end{tabular}

Mediums followed by letters representing their statistical significance (Anova 2-criteria/Tukey, alfa=5\%).

Capital letters compare control methods in the challenge factor's levels and lowercase letters compare the erosive challenges in the control method's level.

When erosive challenges were analyzed within each level of preventive methods, it was verified that in the groups exposed to the negative control (absence of protection) and to topical application of fluoride, there was a significant reduction in the percentage of continuous margins after 9 and 18 DES-RE cycles, compared to the absence of challenge. In the groups treated with the resin-modified glass ionomer varnish and resin sealants, no differences were observed in the percentage of continuous margins between the three challenges.

In relation to the preventive methods at each level of erosive challenge, the percentage of continuous margins in the absence of an erosive challenge and after 9 cycles was similar between the methods of surface protection. However, after 18 cycles, the number of continuous margins protected with resin-modified glass ionomer varnish were higher than those of the negative control. The groups protected with topical application of fluoride and resin sealant presented intermediate values, with no significant differences among the groups.

\section{Internal margin}

The $\%$ of internal data of continuous margins found in the experimental groups are shown in Table 2. No significant effects were observed internally; neither between the statistical interaction among factors under study ( $p=0.97)$, nor between the levels of each factor (preventive method $p=0.86$, erosive challenge $p=0.85$ ).

Table 2. Mean (standard deviation) of experimental groups - Internal margin

\begin{tabular}{lccc}
\hline \multirow{2}{*}{ Erosive challenge control methods } & \multicolumn{3}{c}{ Erosive Challenge } \\
\cline { 2 - 4 } & Negative control & $\mathbf{9}$ cycles & $\mathbf{1 8}$ cycles \\
\hline Negative control & $99.4(1.2)$ & $99.3(1.5)$ & $99.4(1.1)$ \\
\hline Topical application of fluoride & $99.8(0.7)$ & $99.4(1.2)$ & $99.5(1.0)$ \\
\hline Resin-modified glass ionomer varnish & $99.8(0.6)$ & $99.6(0.8)$ & $99.4(1.2)$ \\
\hline Resin sealant & $99.4(1.2)$ & $99.7(0.8)$ & $99.5(1.0)$ \\
\hline
\end{tabular}

Mediums (standard deviation) of continuous internal margins percentage in experimental groups. 


\section{DISCUSSION}

A higher frequency of regurgitation, which consequently increases the frequency of a lowering in the $\mathrm{pH}$ of the oral cavity over a period of time, may be present in individuals with gastroesophageal tract disorders. In these patients, the DES-RE mechanism is initiated at each episode of regurgitation, which can last between 1 and 2 minutes in the awake patient and between 15 and 20 minutes during sleeping. Saliva helps to buffer the $\mathrm{pH}^{9}$. In the present work, the DES-RE mechanism, adapted from the methodology of Austin et al. ${ }^{14}$, was used with the addition of 18 cycles of DES-RE, simulating moments of gastroesophageal crisis.

The evaluation of the restored margins through a stereoscopic microscope can portray possible maladaptation of the composite resin ${ }^{17,18}$. This technique allows possible faults in the tooth-restoration interface to be determined and measured. However, the use of a stereoscopic microscope has limitations. The technique only demonstrates that there is maladaptation, but not the origin of the failure and whether it was due to an operative error, adhesive failure or the erosive challenge that caused material wear, as in the present study.

The present study revealed signs of external degradation at the interface between tooth and restoration, even if minimal, in all the groups. The obtained images were enlarged to visualize the defects produced by the acids ${ }^{17}$, which gave confirmation that exposure to hydrochloric acid at $\mathrm{pH}=2.2$ promotes irreversible changes in the external restoration margins.

When teeth affected by dental erosion are restored, it is important that the adhesive system exhibits good bonding ability to enhance the longevity of the restoration. A three-step etch \& rinse adhesive system was used in the present study. In previous studies, this material was more effective when compared to other systems ${ }^{19,20}$.

The defects found on the eroded margins portray the hydrochloric acid's ability to penetrate the dentin, dissolving the calcium crystals. The hybrid layer formed by the adhesive system seemed to be incapable of containing such damage ${ }^{19-21}$. Thus, it is noted that even with the adhesive system of proven performance, marginal maladaptation is likely to occur due to factors such as morphology and composition of the dental tissue, the intensity of acid challenge episodes and lack of surface protection ${ }^{11,21}$.

In the present study, the amount of external marginal defects increased significantly after erosive challenges in the groups without surface protection (negative control) and in those exposed to topical application of fluoride. However, there was no significant difference in the number of marginal defects when the erosive challenge was increased. Therefore, it was not possible to determine whether the defects existing after 9 DES-RE cycles become more intense after 18 DES-RE cycles, since the methodology only measured the length of the defects, and not in other dimensions. Further studies are therefore indicated to categorize the amplitude of the damage with more precision.

The degradation of the composite subjected to acid exposure can result in softening the monomer, such as Bis-GMA and UDMA ${ }^{22}$. These compounds constitute the 
organic matrix of the composite resins, for example the nanofilled material tested in the present investigation. The softening of the monomers, degradation of the silane interface and the loss of fillers due to the irreversible damage caused by the acid can explain the failures found in the margins of restorations of the present study ${ }^{23}$.

In the present investigation, the hypothesis that methods of surface protection could minimize and prevent damage at the adhesive interface was partially accepted. In the groups where the surface covering was a mechanical barrier using the resin and resin-modified glass ionomer varnish, no significant decrease in the percentage of continuous external margins was observed with the exposure to DES-RE cycles. Unfortunately, the same result was not found using a topical fluoride application.

There are reports that a topical application of fluoride performed with neutral sodium fluoride gel can promote the control and minimization of dental demineralization ${ }^{24,25}$. The fluoride ion, in contact with saliva, forms crystals of calcium fluoride, which can act as a physical barrier to prevent penetration of the acid in the exposed dentin ${ }^{25-27}$. Some studies report that high amounts of fluoride can be retained in dentin, depending on their porosity and water content $27,29,30$. However, the findings of the restored outer margins protected using topical fluoride in the present investigation contradict those of previous studies. The fluoride ion did not prevent the increase of the marginal defects after 9 cycles of DES-RE, although it gave intermediate values after 18 cycles. It is therefore suggested that the frequency of the challenges, the dissolving ability of $\mathrm{NaF}$ and the low $\mathrm{pH}$ of the gastric acid tested may be related to this result ${ }^{25,26}$. Moreover, it should also be considered that clinically there would be the additional, effect of mechanical brushing forces, which would make a continual presence of fluoride deposits even more difficult to maintain ${ }^{29}$. Also, the hypothesis that the acidity of some fluoride gels may influence the degradation of the surface of the restorative material should be taken into account, especially in patients with aesthetic restorations of composite resin ${ }^{18}$.

In the present investigation, the percentage of continuous margins in the group with a physical barrier provided by the resin sealant did not significantly alter even after erosive challenges. This result might be related to the ability of the sealant to penetrate into irregularities present in the tooth-restoration interface, thus delaying the degradation of the margin and preventing possible marginal infiltration ${ }^{9,10}$. The use of a resin sealant could have decreased the progression of surface wear and acted as a physical barrier against acid attacks ${ }^{8,28}$.

However, there are conflicting results in the literature regarding the effectiveness of resin sealants. It has been reported that sealants cannot minimize marginal infiltration because of their relatively high viscosity and incomplete wetting at the composite resin restoration interface ${ }^{31}$. The thickness of the applied material will also be low, which may also facilitate its' vulnerability to removal because only superficial defects are filled ${ }^{32}$.

It is important to note that although the percentage of continuous margins for the resin sealant remained unchanged throughout the different challenges, after 18 cycles of DES-RE, the result was intermediate. Due to the monomeric nature and absence of filler particles in the resin sealant, it is possible that a greater absorption 
of water triggered the hydrolysis of the polymers ${ }^{7}$. This effect has already been documented previously, being associated with staining and pigmentation of the composite resin restoration?

The resin-modified glass ionomer varnish was also able to preserve the adhesive margins, even after the erosive challenges. However, an interesting result with this material was that it presented a significantly higher number of continuous margins after 18 DES-RE cycles. In dental enamel, a resin-modified glass ionomer varnish exhibits good remineralization and demineralization control11,13,25,28, probably due to the mechanism of long-term release of calcium, phosphorus and fluoride, adhesion to enamel and dentine and consequent sealing ability ${ }^{6,11,25}$. The glass-ionomer sealant modified by resin has important properties that enable maintenance of the dental organic matrix and conservation of the remaining substrate after the erosion process ${ }^{11,25,28}$

The manufacturer of Clinpro XT Varnish gives its composition as; polyalkenoic acid patented and modified by methacrylate, 2-hydroxyethyl methacrylate (HEMA), water, calcium glycerophosphate, Bis-GMA and fluoraluminiosilicate glass. The instant release of fluoride from the glass-ionomer modified by composite resin is triggered by chemical bonds carried out on the surface of the particle of a compound called fluoroaminosilicate, also described by the manufacturer. Calcium glycerophosphate is present throughout the lifespan of the material, forming a reservoir until its' complete disappearance from the surfaces of composite resin and tooth ${ }^{28,33,34}$. Thus, there is a need for more in vivo studies on its behavior in clinical settings.

The polyalkenoic acid present in the varnish can also occlude dentin tubules by the formation of an amorphous mineral similar to apatite, providing less exposure of the organic demineralized organic matrix (DOM) to acid degradation ${ }^{13}$. Therefore a sealant provides a physical and mechanical reduction in the diameter of the canaliculi that protect the dentin from future acid attacks, through this acid-resistant layer formed within the substrate $e^{12,34}$.

There is an important relationship between the preservation of the demineralized organic matrix layer and the progression of dental erosion. The proteolytic degradation of the DOM results in an increase in the rate of erosion, since this layer has the capacity of to buffer acids, which prevents the aggravation of the demineralization ${ }^{29}$. The resin-modified glass ionomer varnish component of the barrier material may also have the ability to penetrate into the organic matrix of the dental substrate, promoting stabilization of the collagen against the acidic environment 25,35 .

When analyzing the condition of the margin of the restorations, the loss of structure from the composite resin and the dentin must be taken into account, since they maybe affected differently by the exposure to acid, as they react differently to the acid $^{18}$. In this sense, it is believed that, in the present study, the good results obtained with the glass-ionomer sealant after 18 cycles of DES-RE are due, mainly to the preservation of the dental structure in the eroded margin. However, further studies regarding the use of this material should be performed.

Considering the limitations of the present in vitro study, it can be concluded that, in the face of simulated endogenous erosion, resin and resin-modified glass ionomer var- 
nish have the potential to prevent damage to the margins of composite resin adhesive restorations. However, the glass ionomer varnish material seems to be less affected by the erosive challenge intensity, which is relatively important in the control of dental erosion in patients with gastroesophageal disorders.

\section{ACKNOWLEDGMENTS}

Authors thank FAPESB, grant RED 019/2013 and 3M-ESPE for material support for this investigation.

\section{CONFLICTS OF INTEREST STATEMENT}

The authors report no conflicts of interest in this work.

\section{REFERENCES}

1. Schwendicke F, Felstehausen G, Carey C, Dörfer C. Comparison of four methods to assess erosive substance loss of dentin. PLoS One. 2014 Sep 17;9(9):e108064. doi: 10.1371/journal.pone.0108064.

2. Caneppele TMF, Jeronymo RDI, Di Nicoló, R, Araújo MAMD, Soares LES. In Vitro assessment of dentin erosion after immersion in acidic beverages: surface profile analysis and energy-dispersive X-ray fluorescence spectrometry study. Braz Dent J. 2012;23(4):373-8.

3. Scaramucci T, Borges AB, Lippert F, Zero DT, Aoki IV, Hara AT. Anti-erosive properties of solutions containing fluoride and different film forming agents. J Dent. 2015 Apr;43(4):458-65. doi: 10.1016/j.jdent.2015.01.007.

4. Cramer NB, Stansbury JW, Bowman, CN. Recent Advances and developments in composite dental restorative materials. J Dent Res. 2011 Apr;90(4):402-16. doi: 10.1177/0022034510381263.

5. Bartlett D, Sundaram G, Moazzez R. Trial of protective effect of fissure sealants, in vivo, on the palatal surfaces of anterior teeth, in patients suffering from erosion. J Dent. 2011 Jan;39(1):26-9. doi: 10.1016/j.jdent.2010.09.007

6. Yamazaki H, Litman A, Margolis HC. Effect of fluoride on artificial caries lesion progression and repair in human enamel: regulation of mineral deposition and dissolution under in vivo-like conditions. Arch Oral Biol. 2007 Feb;52(2):110-20.

7. Kina M, Lopes GC, Monteiro Junior S. [Influence of surface sealant on microleakage and staining of composite resin restorations]. RPG Rev pos-grad. 2011;18(3):148-53. Portuguese.

8. Oliveira GC, Boteon AP, Ionta FQ, Moretto MJ, Honório HM, Wang L, et al. In vitro effects of resin infiltration on enamel erosion inhibition oper dent. Oper Dent. 2015 Sep-Oct;40(5):492-502. doi: 10.2341/14-162-L.

9. Ranjitkar S, Kaidonis JA, Smales RJ. Gastroesophageal reflux disease and tooth erosion. Int J Dent. 2012;2012:479850. doi: 10.1155/2012/479850.

10. Prakki A, Ribeiro LWJ, Cilli R, Mondelli RFL. Assessing the tooth-restoration interface wear resistance of two cementation techniques: effect of a surface sealant. Oper Dent. 2005 Nov-Dec;30(6):739-46.

11. Sohn S, Yi K, Son HH, Chang J. Caries-preventive activity of fluoride-containing resin-based desensitizers. Oper Dent. 2012 May-Jun;37(3):306-15. doi: 10.2341/11-007-L.

12. Suge T, Ishikawa K, Kawasaki A, Suzuki K, Matsuo T, Noiri Y et al. Calcium phosphate precipitation method for the treatment of dentin hypersensitivity. Am J Dent. 2002 Aug;15(4):220-6. 
13. Zhou SL, Zhou J, Watanabe S, Watanabe K, Wen LY, Xuan K. In vitro study of the effects of fluoride-releasing dental materials on remineralization in an enamel erosion model. J Dent. 2012 Mar;40(3):255-63. doi: 10.1016/j.jdent.2011.12.016.

14. Austin RS, Stenhagen KS, Hove LH, Dunne S, Moazzez R, Bartelett DW, et al. A qualitative and quantitative investigation into the effect of fluoride formulations on enamel erosion and erosionabrasion in vitro. J Dent. 2011 Oct;39(10):648-55. doi: 10.1016/j.jdent.2011.07.006.

15. Queiroz MMV, Shibasaki PAN, Lima MJP, Araújo RPC, Foxton RM, Cavalcanti AN. Effect of erosion and methods for its control on the surface roughness of composite resin. Rev Odonto Cienc 2017;32(2):88-93.

16. Bortolotto T, Doudou W, Kunzelmann KH, Krejci I. The competition between enamel and dentin adhesion within a cavity: An in vitro evaluation of class V restorations. Clin Oral Investig. 2012 Aug;16(4):1125-35. doi: 10.1007/s00784-011-0623-y.

17. Soares LE, de Oliveira R, Nahórny S, Santo AM, Martin AA. Micro energy-dispersive X-ray fluoresence mapping of enamel and dental materials after chemical erosion. Microsc Microanal. 2012 Oct;18(5):1112-7. doi: 10.1017/S1431927612001535.

18. Yu H, Buchalla W, Cheng H, Wiegand A, Attin T. Topical fluoride application is able to reduce acid susceptibility of restorative material. Dent Mat J. 2012;31(3):433-42.

19. Lenzi TL, Raggio DP, Soares FZM, Rocha RO. Bonding performance of a multimode adhesive to artificially-induced caries-affected primary dentin. J Adhes Dent. 2015 Apr;17(2):125-31. doi: 10.3290/j.jad.a34058.

20. Muñoz MA, Luque I, Hass V, Reis A, Loguercio AD, Bombarda NHC. Immediate bonding properties of universal adhesives to dentine. J Dent. 2013 May;41(5):404-11. doi: 10.1016/j.jdent.2013.03.001.

21. Flury S, Koch T, Peutzfeldt A, Lussi A, Ganss C. The effect of a tin-containing fluoride mouth rinse on the bond between resin composite and erosively demineralised dentin. Clin Oral Investig. 2013 Jan;17(1):217-25. doi: 10.1007/s00784-012-0697-1.

22. Honório HM, Rios D, Francisconi LF, Magalhães AC, Machado MA, Buzalaf MA. Effect of prolonged erosive pH cycling on different restorative materials. J Oral Rehabil. 2008 Dec;35(12):947-53. doi: 10.1111/j.1365-2842.2008.01856.x.

23. Kaur S, Makkar S, Kumar R, Pasricha S, Gupta P. Comparative evaluation of surface properties of enamel and different esthetic restorative materials under erosive and abrasive challenges: An in vitro study. Indian J Dent. 2015 Oct-Dec;6(4):172-80. doi: 10.4103/0975-962X.165047.

24. Elkassas D, Arafa A. Remineralizing efficacy of different calcium-phosphate and fluoride based delivery vehicles on artificial caries like enamel lesions. J Dent. 2014 Apr;42(4):466-74. doi: 10.1016/j.jdent.2013.12.017.

25. Martins, VL; Ramos, RVC; Lima, MJP; de Araújo, RPC; Cavalcanti, AN. Effect of surface protection on the permeability of eroded dentin. J Conserv Dent. 2018 Jan-Feb;21(1):16-20. doi: 10.4103/JCD.JCD_281_16.

26. Algarni AA, Lippert F, Hara AT. Efficacy of stannous, fluoride and their their combination in dentin erosion prevention in vitro. Braz Oral Res. 2015;29. pii: S1806-83242015000100276. doi: 10.1590/1807-3107BOR-2015.vol29.0081.

27. Lussi A, Carvalho TS. The future of fluorides and other protective agents in erosion prevention. Caries Res. 2015;49 Suppl 1:18-29. doi: 10.1159/000380886.

28. Owens BM, Johnson WW. Effect of new generation surface sealants on the marginal permeability of class $V$ resin composite restorations. Oper Dent. 2006 Jul-Aug;31(4):481-8.

29. Ganss C ,Klimek V,.Schürmann A. Effects of two fluoridation measures on erosion progression in human enamel and dentine in situ. Caries Res. 2004 Nov-Dec;38(6):561-6. 
30. Ganss C, Klimek J, Schäffer U, Spall T. Effectiveness of two fluoridation measures on erosion progression in human enamel and dentine in vitro. Caries Res. 2001 Sep-Oct;35(5):325-30.

31. Takeuchi CY, Flores VO, Dibb RP, Panzeri H, Lara EH, Dinelli W. Assessing the surface roughness of a posterior resin composite: effect of surfasse sealing. Oper Dent. 2003 May-Jun;28(3):281-6.

32. Bertrand MF, Leforestier E, Muller M, Lupi-Pégurier L, Bolla M. Effect of surface penetrating sealant on sur- face texture and microhardness of composite resins. J Biomed Mater Res. 2000;53(6):658-63.

33. Orchardson R, Gillam D. Managing dentiny hypersensitivy. J Am Dent Assoc. 2006 Jul;137(7):990-8; quiz 1028-9.

34. Chiga S, Toro CV, Lepri TP, Turssi CP, Colucci V, Corona SA, et al. Combined effect of fluoride varnish to Er:YAG or Nd:YAG laser on permeability of eroded root dentine. Arch Oral Biol. 2016 Apr;64:24-7. doi: 10.1016/j.archoralbio.2015.12.006.

35. Zimmerli B, Munck J, Lussi A, Lambrechts P, Meerbeek BV. Long-term bonding to eroded dentin requires superficial bur preparation. Clin Oral Investig. 2012 Oct;16(5):1451-61.

doi: 10.1007/s00784-011-0650-8. 